NASA/TM—2007-214908

\title{
Effects of Unsteadiness Due to Wake Passing on Rotor Blade Heat Transfer
}

Ali A. Ameri

University of Toledo, Toledo, Ohio

David L. Rigby

QSS Group, Inc., Cleveland, Ohio

James Heidmann

Glenn Research Center, Cleveland, Ohio

Erlendur Steinthorsson

$A \&$ E Consulting, Westlake, Ohio

John C. Fabian

Glenn Research Center, Cleveland, Ohio 


\section{NASA STI Program . . . in Profile}

Since its founding, NASA has been dedicated to the advancement of aeronautics and space science. The NASA Scientific and Technical Information (STI) program plays a key part in helping NASA maintain this important role.

The NASA STI Program operates under the auspices of the Agency Chief Information Officer. It collects, organizes, provides for archiving, and disseminates NASA's STI. The NASA STI program provides access to the NASA Aeronautics and Space Database and its public interface, the NASA Technical Reports Server, thus providing one of the largest collections of aeronautical and space science STI in the world. Results are published in both non-NASA channels and by NASA in the NASA STI Report Series, which includes the following report types:

- TECHNICAL PUBLICATION. Reports of completed research or a major significant phase of research that present the results of NASA programs and include extensive data or theoretical analysis. Includes compilations of significant scientific and technical data and information deemed to be of continuing reference value. NASA counterpart of peer-reviewed formal professional papers but has less stringent limitations on manuscript length and extent of graphic presentations.

- TECHNICAL MEMORANDUM. Scientific and technical findings that are preliminary or of specialized interest, e.g., quick release reports, working papers, and bibliographies that contain minimal annotation. Does not contain extensive analysis.

- CONTRACTOR REPORT. Scientific and technical findings by NASA-sponsored contractors and grantees.
- CONFERENCE PUBLICATION. Collected papers from scientific and technical conferences, symposia, seminars, or other meetings sponsored or cosponsored by NASA.

- SPECIAL PUBLICATION. Scientific, technical, or historical information from NASA programs, projects, and missions, often concerned with subjects having substantial public interest.

- TECHNICAL TRANSLATION. Englishlanguage translations of foreign scientific and technical material pertinent to NASA's mission.

Specialized services also include creating custom thesauri, building customized databases, organizing and publishing research results.

For more information about the NASA STI program, see the following:

- Access the NASA STI program home page at http://www.sti.nasa.gov

- E-mail your question via the Internet to help@sti.nasa.gov

- Fax your question to the NASA STI Help Desk at 301-621-0134

- Telephone the NASA STI Help Desk at 301-621-0390

- Write to: NASA Center for AeroSpace Information (CASI) 7115 Standard Drive Hanover, MD 21076-1320 
NASA/TM-2007-214908

AIAA-2006-3263

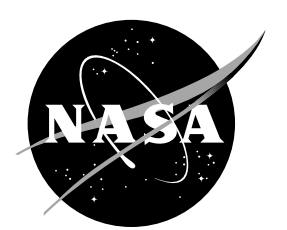

\section{Effects of Unsteadiness Due to Wake Passing on Rotor Blade Heat Transfer}

Ali A. Ameri

University of Toledo, Toledo, Ohio

David L. Rigby

QSS Group, Inc., Cleveland, Ohio

James Heidmann

Glenn Research Center, Cleveland, Ohio

Erlendur Steinthorsson

A \& E Consulting, Westlake, Ohio

John C. Fabian

Glenn Research Center, Cleveland, Ohio

Prepared for the

Ninth Joint Thermophysics and Heat Transfer Conference

cosponsored by the American Institute of Aeronautics and Astronautics and the American Society of Mechanical Engineers

San Francisco, California, June 5-8, 2006

National Aeronautics and

Space Administration

Glenn Research Center

Cleveland, Ohio 44135 
This report contains preliminary findings, subject to revision as analysis proceeds.

Trade names and trademarks are used in this report for identification only. Their usage does not constitute an official endorsement, either expressed or implied, by the National Aeronautics and Space Administration.

This work was sponsored by the Fundamental Aeronautics Program at the NASA Glenn Research Center.

Level of Review: This material has been technically reviewed by technical management.

Available from

NASA Center for Aerospace Information 7115 Standard Drive

Hanover, MD 21076-1320
National Technical Information Service 5285 Port Royal Road Springfield, VA 22161 


\title{
Effects of Unsteadiness Due to Wake Passing on Rotor Blade Heat Transfer
}

\author{
Ali A. Ameri \\ University of Toledo \\ Toledo, Ohio 43606 \\ David L. Rigby \\ QSS Group, Inc. \\ Cleveland, Ohio 44135 \\ James Heidmann \\ National Aeronautics and Space Administration \\ Glenn Research Center \\ Cleveland, Ohio 44135 \\ Erlendur Steinthorsson \\ A \& E Consulting \\ Westlake, Ohio 44145 \\ John C. Fabian \\ National Aeronautics and Space Administration \\ Glenn Research Center \\ Cleveland, Ohio 44135
}

\begin{abstract}
In a gas turbine engine, the turbine rotor blades are buffeted by the wakes of the vanes located upstream. There is a transient effect from the passing of wakes on the blade heat transfer. This transient effect has been computed for a representative rotor by introducing a wake upstream via an unsteady inlet flow boundary condition, or "gust" condition. Two cases of turbulent flow and laminar flow with Reynolds numbers of 385,000 and 385 respectively were considered. For the turbulent flow case a quasi-steady calculation was also performed. The variation in the unsteady heat transfer coefficient was found to be as high as 120 percent of the mean. For the turbulent flow case a quasi-steady calculation was also performed. The time mean of the unsteady heat transfer, the mean of the quasisteady variations and the steady results agree reasonably well on all blade locations except for the turbulent results which differ near the leading edge. The quasi-steady heat transfer results do not agree with the instantaneous unsteady results, although the time-mean values are similar.
\end{abstract}

\section{Nomenclature}

C axial chord length

h wall heat flux (Tw-Tt)

$\mathrm{k}_{\mathrm{W}} \quad$ fluid conductivity at the wall

$\mathrm{Nu} \quad$ Nusselt number $=\mathrm{hC} / \mathrm{k}_{\mathrm{w}}$

$p \quad$ static pressure

$p_{0} \quad$ relative total inlet pressure

$\mathrm{Re} \quad$ Reynolds number based on the inlet velocity and axial chord

$\mathrm{S} \quad$ wetted surface distance measure from the geometric stagnation point negative on the pressure side and positive on the suction side

$\mathrm{Tt}, \mathrm{Tw} \quad$ inlet total temperature and wall temperature

$\mathrm{U}$ characteristic velocity, inlet axial velocity

X axial location

$\omega_{\mathrm{r}} \quad$ reduced frequency $=\omega \mathrm{C} / \mathrm{U}$ 


\section{Introduction}

Turbine blades operate in an environment where the reduced frequency $(\omega \mathrm{C} / \mathrm{U})$ is outside of the small reduced frequency regime. The effect of the unsteadiness on the blade surface heat transfer and its significance is unclear. The effect of unsteady flow on heat transfer in other areas of turbine blades such as the blade tip and downstream of cooling holes are of interest. In the case of cooling holes, the time variation in discharge pressure forced by the passing of wakes causes the cooling stream to vary in time. The effect of this oscillation on the overall film-cooling effectiveness and the rate of heat transfer may be non-negligible and one which could be further investigated using unsteady CFD. The type of studies just described requires a three-dimensional unsteady calculation which our current work is planning to address. The work described herein is, however, limited to the surface heat transfer on a radial section of a blade subjected to wake induced buffeting, and is free from other complicating factors.

The effect of flow unsteadiness on heat transfer has been studied under laminar flow conditions for a cylinder in an oscillating stream. The conclusion is that the effect of periodic unsteadiness, under the conditions of reduced frequencies that are much smaller than unity, can be neglected, and instead replaced by quasi-steady results. Quasisteady conditions are defined by Lighthill as the state of the boundary layer that is appropriate to steady flow at the instantaneous value of the free stream conditions at the edge of the boundary layer. In effect, if the unsteady acceleration of oscillations is small this method can be utilized for simplification. Under the conditions of quasisteady flow, described by Lighthill (ref. 1), the boundary conditions imposed on the boundary layer are not time variant. We have interpreted the quasi-steady condition as the condition for which one can specify the locations of the wake at the inlet and then solve the steady problem under those conditions. It should however be noted, that freezing the inlet boundary condition (i.e., keeping the wake from moving) results in the wake approaching the blade at a different relative angle. It will be seen later that this boundary condition still results in an average heat transfer that is almost identical to the time mean heat transfer but with the instantaneous value quite different than the unsteady value.

The desire to obtain a complete unsteady flow and heat transfer solution in turbine blades is tempered by the enormity of the resources required. As the computational capabilities grow, obtaining unsteady solutions using turbulence closure models have become more realistic and indeed Unsteady Reynolds Averaged Navier-Stokes (URANS) solutions are becoming common. Two-dimensional solutions of unsteady rotor-stator interaction have been accomplished and such calculations have been used for clocking the blade rows (ref. 2) aimed at improving the efficiency of turbines. Unsteady RANS calculations including the rotor/stator interaction have also been performed to predict unsteady heat transfer on blades and vanes. Those would include the work of Rao et al. (ref. 3) who used a 2 to 3 vane to stator blade count and a 2-D code and the work of Michelassi et al. (ref. 4) who rescaled the blade to maintain a one to one ratio of the vane-blade count and used a 3-D methodology to calculate the blade heat transfer. Abhari et al. (ref. 5) used the code UNSFLO which uses a transformed Euler equation to accommodate the vane to blade count ratio. The aerodynamics of passing of the wakes and the unsteady effect they have on low pressure turbine blades is dealt with in detail in a review paper by Hodson and Howell (ref. 6). The main emphasis as related to low pressure blades is on the common problem of flow separation at condition of cruise speeds at high altitude. Under those conditions, the flow on the suction side of the rotor blade is laminar and prone to separation. The unsteady flow has the potential to be exploited to help energize the boundary layer and thus lessen the losses that would otherwise be produced by the separation. Heidmann performed an analysis (ref. 7) and Heidmann et al. performed an experiment (ref. 8) using unsteady wakes produced by a row of rotating rods passing over a downstream annular turbine blade cascade with showerhead film cooling. Unsteady cases were studied for a range of reduced frequencies as well as no-wake and quasi-steady wake cases. They found that increasing the frequency of rotation has a deteriorating effect on the effectiveness of film cooling. No heat transfer measurements were performed. In this paper we mainly address the issue of unsteady heat transfer on high pressure turbine blades. We will explore the suitability of quasi-steady calculations to replace the unsteady calculations as is at times done to reduce computational time. 


\section{Calculations}

Three-dimensional, URANS calculations were performed to predict heat transfer rate on a rotor blade. The flow was solved in an annular section assuming a slip boundary condition on boundaries possessing normals in the radial direction. Our simulation included a one to one and a two to one vane blade ratio with a gust type boundary condition at the inlet. The guide vane flow was calculated using the same code but in steady mode. The total pressure in the wake thus produced was fitted with a trigonometric function and placed as the boundary condition at the inlet of the rotor. The blade was rotating at $8400 \mathrm{rpm}$. There were 46 vanes and 76 blades ( 0.6 ratio). For the calculations presented here a one to one ratio was used. A one to two vane to blade ratio would be more accurate, but would double the computational cost and was not attempted. To study the effect of the one to one assumption, we doubled the frequency while holding the wake size the same to investigate the effect of frequency. The frequency of the wake thus produced is even higher than the actual configuration but was done to provide insight into the effect of frequency.

The computer code used for this study was the Glenn-HT2000 (Steinthorsson (ref. 7)). This computer code was written using object oriented programming principles and the Fortran 90 programming language. The numerical procedure uses a finite-volume discretization scheme that is second order accurate in time and space. The computer program uses the MPI (Message Passing Interface) parallel processing. The cases were run on 20 processors of a 98 processor Xeon Linux Cluster. The turbulence model used for the calculations was the Low Reynolds number k- $\omega$ model of Wilcox integrating to the walls. The grid used was quite fine adjacent to the blade $\left(\mathrm{y}^{+} \sim 1\right)$, in the boundary layer and in the free stream. The turbulence model is able to produce an effect similar to the transition from laminar to turbulent flow. In practice however, the transition is not guaranteed to be in the appropriate location. In fact, it is often triggered very near the leading edge which is what occurred in our computations making them fully turbulent except near the leading edge. The following was investigated:

1. Unsteady effect of the passing wake on the rotor blade row downstream for a laminar and two turbulent cases at 0.44 and 0.88 reduced frequency. Unsteady and time average.

2. Steady calculation particular to the average inlet condition of the unsteady case.

3. Quasi-steady flow calculations and determination of the ensemble average of the blade heat transfer.

4. Laminar flow calculation of heat transfer over the blade.

The quasi-steady case was performed as a series of 32 steady calculations with the wake profile specified at equallyspaced intervals across the inlet. This was done to determine if the motion of the wake passing is important relative to the simple presence of the wake. In effect, the quasi-steady case is equivalent to the limiting case of zero reduced frequency.

The unsteady solution process was started from a converged steady initial solution and continued for several cycles until a transient periodic solution to the blade heat transfer was achieved. The final time step was chosen by progressively reducing the time step until there was little change in the unsteady results. The convergence efficiency was also considered and it was then decided to cover each period by 640 time steps.

The particular geometry considered for this case was the blade geometry and flow conditions of the GE- $\mathrm{E}^{3}$ (ref. 10). A simplified case and a full three-dimensional geometry were considered. The three-dimensional calculations are still in progress and will be presented elsewhere. The simplified geometry was a thin 'sliver' of the blade for which slip boundary conditions in the upper and lower radial boundaries were specified. There were four grid intervals in the radial direction and the blade-to-blade grid was constructed as shown in figure 1 . The grid was refined to resolve the passing of the wake. A coarse grid does not support the wake and the wake dissipates quickly. The simplified case was set to rotate about the rotation axis and was also subjected to a gust type boundary condition upstream. This case was used to investigate the effects described above. The blade row pressure ratio was 0.44 and rotation rate was $8400 \mathrm{rpm}$. The case was scaled to give a Reynolds number based on the axial chord and inlet velocity of 385,000 for the turbulent flow cases. The Reynolds number for the laminar flow case was 385 . The inlet gust boundary condition was specified such that it has a 15 percent total pressure deficit. It has a background turbulence intensity of 2 percent and reaches an intensity of 3.5 percent in the wake. These values were arrived at after the flow through the vane row upstream was calculated independently. 


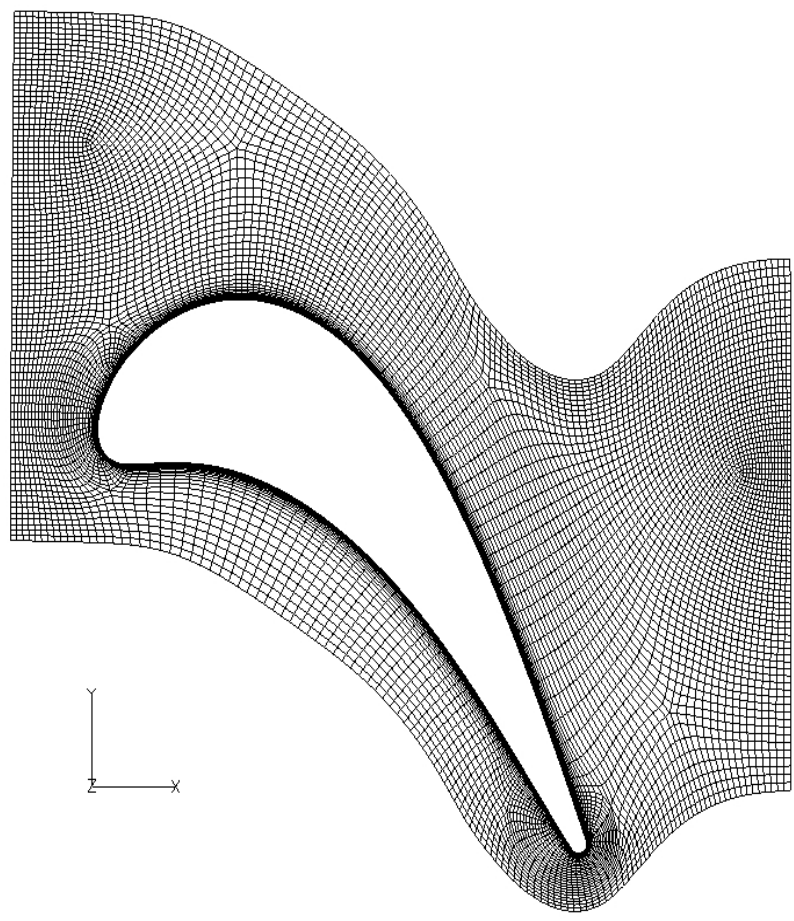

Figure 1.-Blade profile and the grid in a radial plane.

\section{Results}

Figure 2, shows the time variation in the local static pressure on the blade surface. This variation in the surface pressure would have repercussions if film cooling were performed on the blade. In fact, it would have resulted in a pulsation of the filmcooling flow. In the figure, in addition to the time average of the pressure we are showing the pressure distribution resulting from a steady calculation. The difference in the steady solution and the time dependent solutions with the wake is obvious. The difference is attributable to the difference in the incidence angle which would be less steep, on the average, due to the presence of the wake. In other words, because we hold the absolute angle as fixed, the reduced velocity in the wake produces a reduced relative angle of attack. This is an important point to consider when running a CFD code for a rotor in steady mode.

Figure 3 shows the unsteady heat transfer under laminar flow conditions. The time averaged values and steady results are also shown in that figure. Those differences are quite small. As the flow is

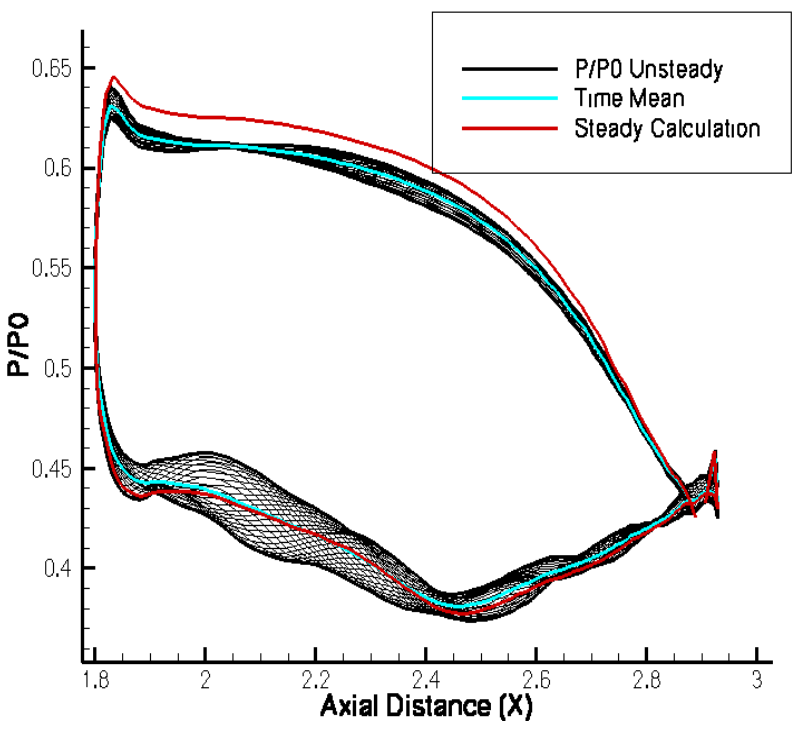

Figure 2.--Relative pressure distribution versus axial distance from the leading-edge. $\mathrm{Re}=385,000$ and $\omega_{\mathrm{r}}=0.44$. purely laminar, the unsteady variation in heat transfer has to be due to flow acceleration. The correlation coefficient between the unsteady components of shear and Nusselt number was computed and was found to have a value near unity. The correlation was computed taking into account all the points on the blade surface over a complete period. The interpretation is that the heat transfer increase/reduction is due to flow acceleration/deceleration under low Reynolds number conditions. The 


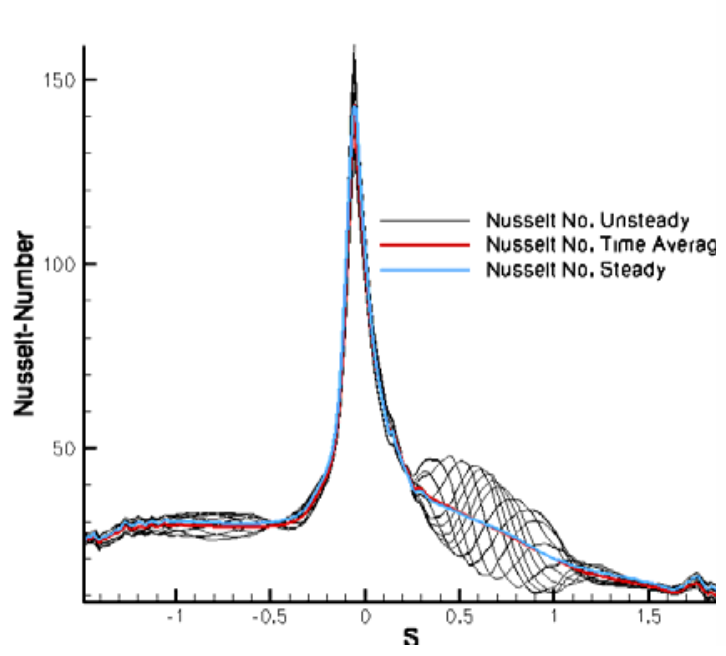

Figure 3.-Nusselt Number versus wetted distance for laminar flow. $\operatorname{Re}=385$, and $\omega_{r}=$ 0.44 .

good correlation suggests that there is not a large lag between these two effects in laminar flow situations. Figure 4 is a plot of Nusselt number for turbulent flow over the rotor blade, the difference between the average of unsteady calculations over a period and steady calculations does not appear to be large except near the leading edge. This may be due to the differences in the incidence angle or the unsteady transition effect or both. An analysis of the unsteady components of shear and Nusselt number yielded a small correlation coefficient. This assertion can be verified by noting that the mean heat transfer and steady value are matched near the leading edge for the laminar flow case. The effect was explained by Dullenkopf and Mayle (ref. 11) who also proposed a transition model which help predict the time average heat transfer on the blade. This model was used in a calculation of heat transfer over a rotor blade. (Ameri and Arnone (ref. 12)). The real effect is not fully apparent here since the model utilized in this work does not include a physically based bypass transition model. In many instances, such as instances in which there is film cooling near the leading edge, or large enough adverse pressure gradient, transition does occur early. The relative magnitude of the envelope obtained for the laminar and the turbulent flow calculations in figures 3 and 4 is shown in figure 5. The figure shows that the unsteady variation around the mean can be as large as 110 percent of the mean. It is interesting that the unsteady variation experiences a precipitous drop once it gets to the uncovered portion of the blade.

In figure 6 the vector plots correspond to the unsteadiness (instantaneous - time mean) at two different phases of the periodic unsteady wake passing for the turbulent flow computations. The shaded background is the entropy rise. The lighter areas correspond to the wake locations.

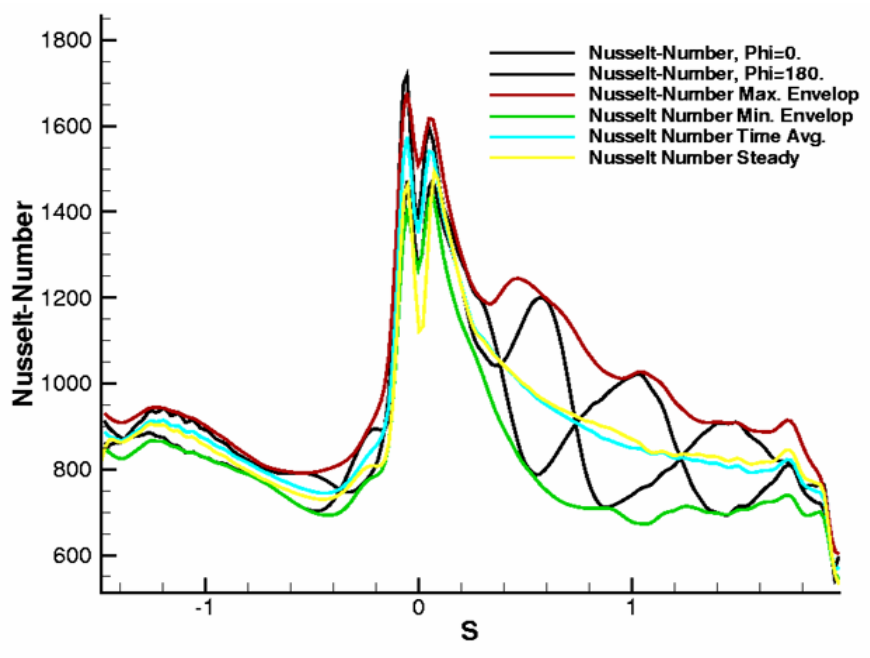

Figure 4.--Nusselt Number versus wetted distance for turbulent flow calculations. $\mathrm{Re}=$ 385,000 and $\omega_{\mathrm{r}}=0.44$.

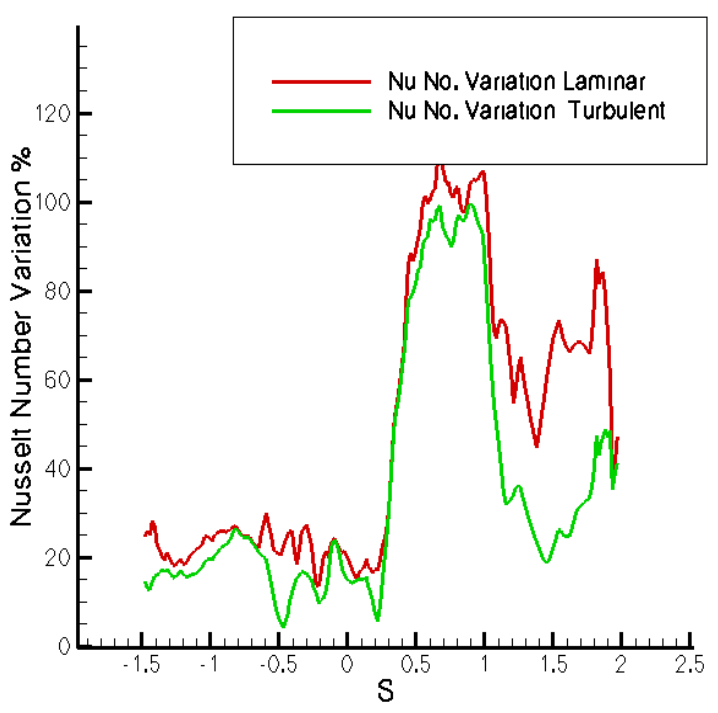

Figure 5.-Percent Variation in Nusselt No. (Numax$\left.\mathrm{Nu} u_{\text {Min }}\right) / \mathrm{Nu}_{\text {Avg }}$ versus axial distance from the leadingedge. 

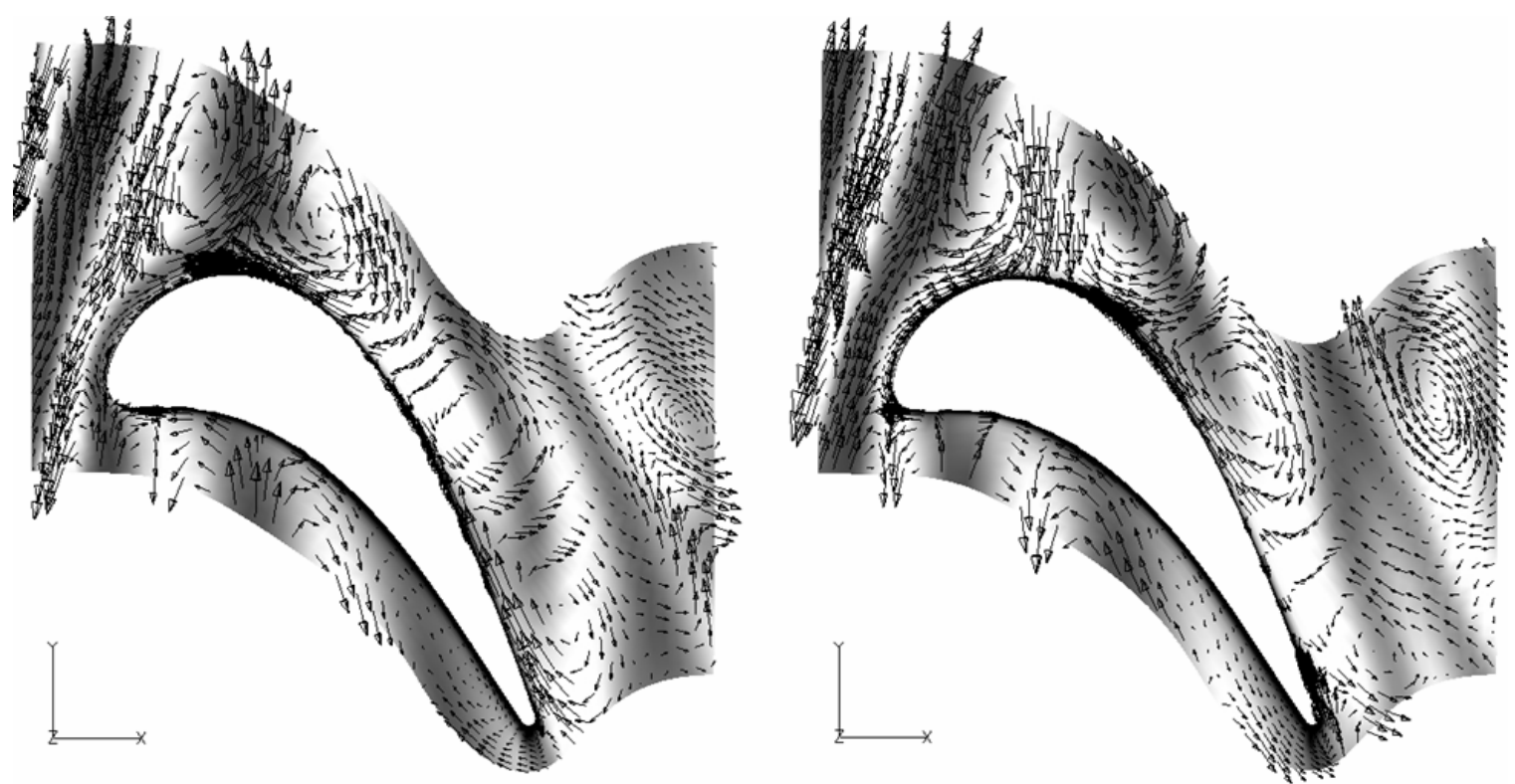

Figure 6.-View of unsteady component of velocity distribution at two different snapshots in time $\operatorname{Re}=385,000$ and $\omega_{\mathrm{r}}=0.44$.

Figure 7 shows the unsteady heat transfer for the same flow as in figure 4 except that the wakes occur twice as often. The motivation for this exercise was explained earlier. The figure shows that the size of the unsteady heat transfer envelope has been reduced considerably compared to figure 4 . As the case in figure 4 was run with a one to one ratio of vanes to blades (itself too fast by a factor of 1.6), it may therefore be concluded that running with the proper ratio of vanes to blades would likely result in even a larger unsteady heat transfer envelope.

\section{Quasi-Steady Results}

There have been instances in which workers have used the quasi-steady conditions to simulate unsteady conditions. As Lighthill (ref. 1) points out this condition would be a good substitute for the unsteady case as long as the reduced frequency is small. In order to obtain quasi-steady solutions the

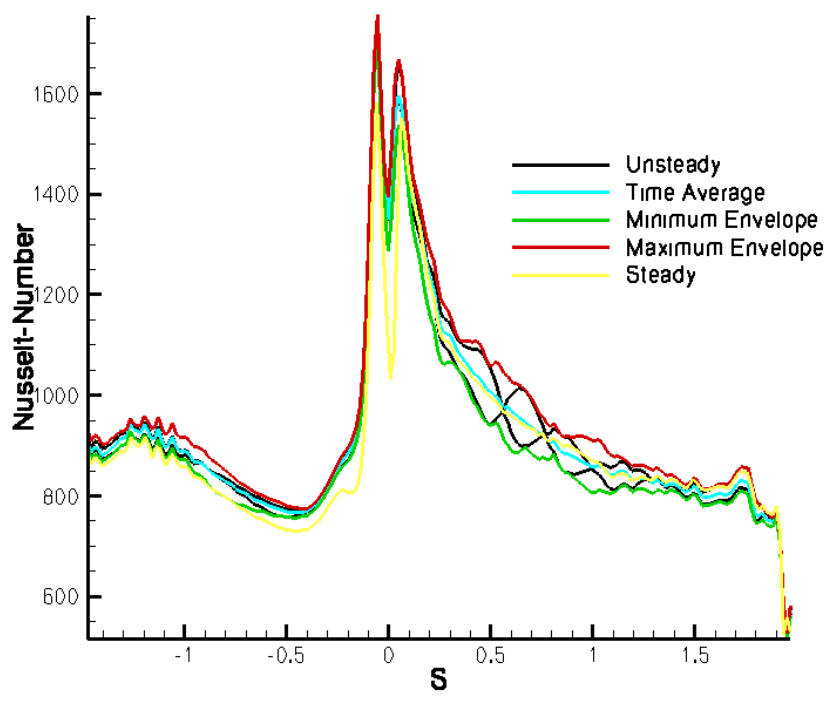

Figure 7.-Higher frequency, Nusselt number versus surface wetted distance. $\operatorname{Re}=385,000$ and $\omega_{r}=0.88$. wake was moved on a number of locations, of equal spacing, along the inlet boundary and corresponding steady solutions was obtained for those locations. The solution envelops and the average values are also shown in figure 8. It is observed that the envelope of the unsteady heat transfer (for the lower frequency), in figure 4, is much wider than that of the quasi-steady solution on the suction side. The opposite is observed on the pressure side. The average however, is very close to the average heat transfer obtained for unsteady flow. The difference points to the fact that the quasi-steady solution cannot replace the unsteady solution. But, it is interesting that the cases so far in this work show that either the quasi-steady mean or the steady value can be substituted for the time-mean value. This is especially true on the suction side. On the pressure side, some differences do exist but, the differences may be too small. The one location where the differences appear to exist and could be significant is near the leading edge of the blade. Both the quasi-steady average and steady values are significantly different than average. Figure 9 is the quasi-steady counterpart to figure 6. 


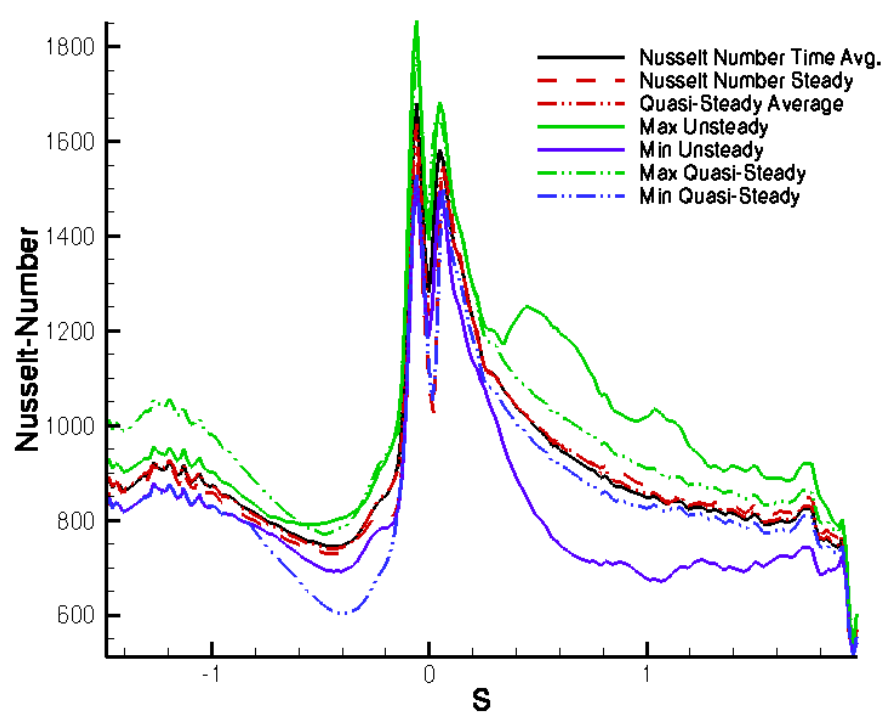

Figure 8.-Quasi-Steady flow, Nusselt number versus surface wetted distance.

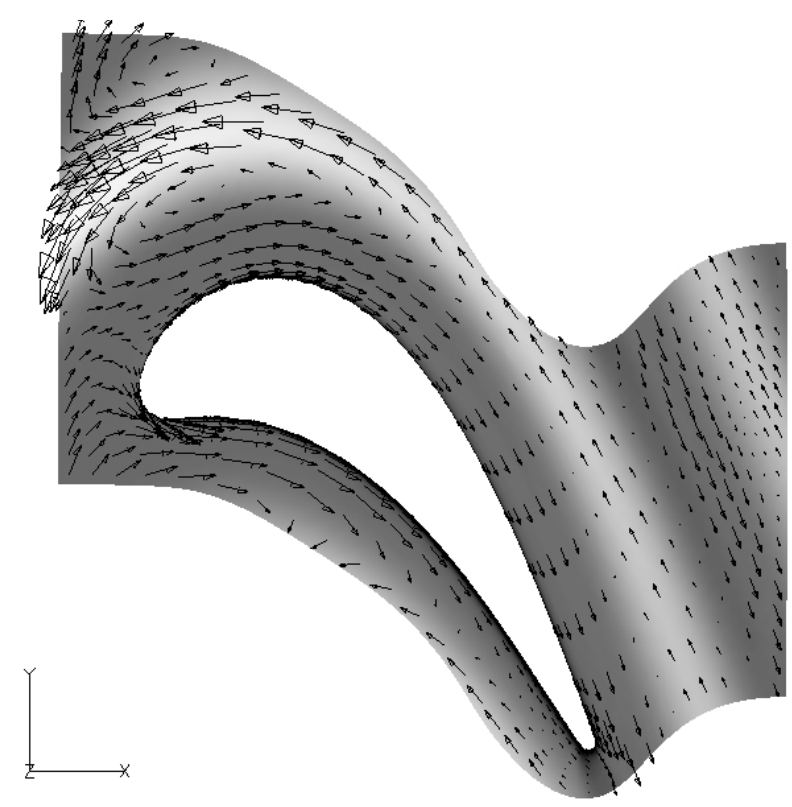

Figure 9.-View of deviation of the velocity vector from the mean for a quasi-steady frame, $\mathrm{Re}=385,000$. 


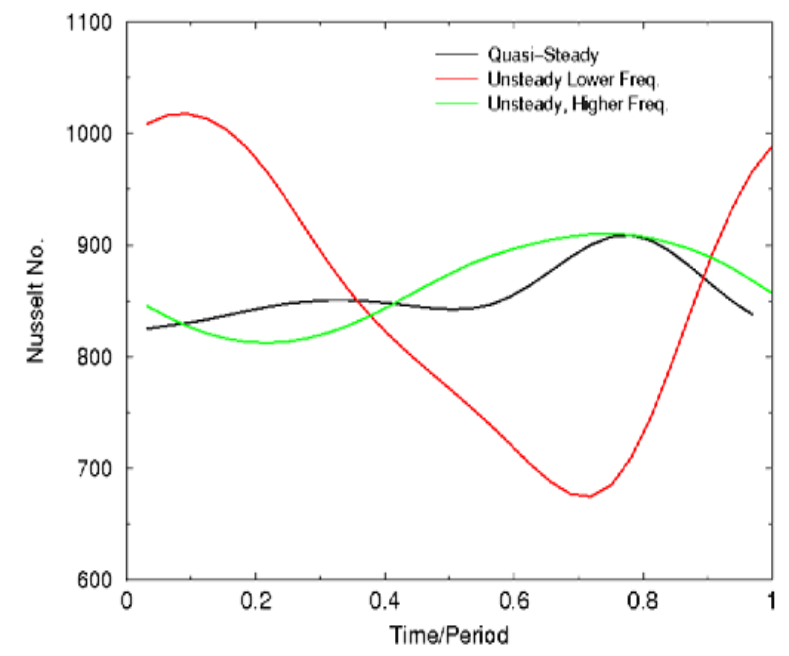

Figure 10.-Nusselt number variation at a point on the suction side of the blade located at $S=1$, downstream of the leading edge for unsteady and quasi-steady computations.

Figure 10 shows the phase variation of Nusselt number for the two blade count ratios considered and the quasisteady solution at those phases for a location one chord length downstream of the leading edge on the suction side of the blade. The figure shows that the quasi-steady values should not be used in place of unsteady values.

\section{Conclusions}

In this paper the effect of unsteady wake in a simplified model of the rotor/stator interaction was considered. The wake was modeled after the vane flow was independently simulated. The results are limited to larger reduced frequencies as compared to those that occurred in the real situation because only one blade periodic case was simulated. Two frequencies were considered. It was found that:

1. The steady heat transfer results are good representation of the mean heat transfer for a clean blade (no film cooling and 2-D flow) for all the cases considered.

2. An average computed from a quasi-steady flow is also a good substitute for time average Nusselt number.

3. The quasi-steady value is not a good representation of the heat transfer on the blade for the unsteady values and in fact the envelopes are substantially different.

4. An increase in "reduced frequency" of wake passing from 0.44 to 0.88 (doubling) resulted in a substantial shrinking of the unsteady heat transfer envelope.

\section{References}

1. M.J. Lighthill, The response of laminar skin friction and heat transfer to fluctuations in the stream velocity," Proc. R. Soc. A224, 1-23(1954).

2. Arnone, Andrea, Marconcini, Michele and Pacciani, Roberto, "Numerical Investigation of Airfoil Clocking in a Three-Stage Low-Pressure Turbine," Journal of Turbomachinery, Jan. 2002, vol. 124, issue 1, pp. 61-68.

3. Rao, K.V.; Delaney, R.A. and Dunn, M.G., "Vane-Blade Interaction in a Transonic Turbine, II-Heat Transfer," Journal of Propulsion and Power 1994, vol. 10, no. 3 (312-317).

4. Michelassi, V.; Martelli, F.; Deons, R.; Arts, T. and Sieverding, C.H.; "Unsteady Heat Transfer in Stator-Rotor Interaction by Two-Equaution Turbulence Mode," Journal of Turbomachinery vol. 121, July 1999. pp. 436447.

5. Abhari, R.S.; Guenette, G.R.; Epstein, A.H. and Giles, M.B., "Comparison of Time-Resloved Turbine Rotor Blade Heat Transfer Measurements and Numerical Calculations," Journal of Turbomachinery, vol. 114, October 1992. pp. 818-827. 
6. Hodson, Howard and Howell, Robert J., "BladeRow Interactions, Transition, and High-Lift Aerofoils in LowPressure Turbines," Annu. Rev. Fluid Mech. 2005. 37:71-98.

7. Heidmann, J.D., 1995, "A Numerical Study of the Effect of Wake Passing on Turbine Blade Film Cooling," AIAA Paper 95-3044.

8. Heidmann, J.D., Lucci, B.L., and Reshotko, E., 2001, "An Experimental Study of the Effect of Wake Passing on Turbine Blade Film Cooling," ASME Journal of Turbomachinery, vol. 123, pp. 214-221, April 2001.

9. Steinthorsson, E., "GlennHT-2000, A Computer Program for the High-Fidelity Calculations of heat transfer in Flows of Interest to Turbomachinery," Unpublished.

10. Halila, E.E. and Lenahan, D.T., and Thomas, L.L., 1982, "Energy Efficient Engine, High Pressure Turbine Test Hardware Detailed Design Report," NASA CR-167955.

11. Dullenkopf, M., and Mayle, R.E., 1994. "The Effect of Incidence Turbulence and Moving Wakes on Laminar Heat Transfer in Gas Turbines," Journal of Turbomachinery, vol. 116, pp. 23-28.

12. Ameri A.A. and Arnone A. "Transition Modeling Effects on Turbine Rotor Blade Heat Transfer Prediction," Journal of Turbomachinery, vol. 118, April 1996, pp. 307-313. 


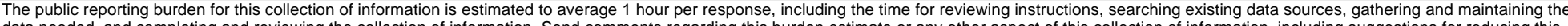

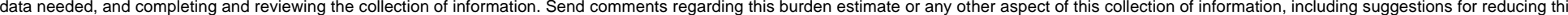

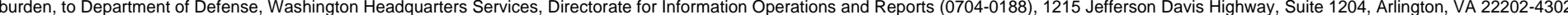

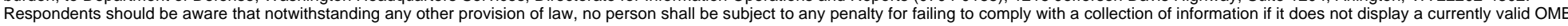
control number.

PLEASE DO NOT RETURN YOUR FORM TO THE ABOVE ADDRESS

\section{REPORT DATE (DD-MM- $Y Y Y Y)$ \\ 2. REPORT TYPE \\ 3. DATES COVERED (From - To)}

01-08-2007

\section{TITLE AND SUBTITLE}

Effects of Unsteadiness Due to Wake Passing on Rotor Blade Heat Transfer

Technical Memorandum

5a. CONTRACT NUMBER

5b. GRANT NUMBER

5c. PROGRAM ELEMENT NUMBER

\section{AUTHOR(S)}

Ameri, Ali, A.; Rigby, David, L.; Heidmann, James; Steinthorsson, Erlendur; Fabian, John,

C.

\section{5d. PROJECT NUMBER}

5e. TASK NUMBER

5f. WORK UNIT NUMBER

WBS 984754.02.07.03.16.06

\section{PERFORMING ORGANIZATION NAME(S) AND ADDRESS(ES)}

National Aeronautics and Space Administration

8. PERFORMING ORGANIZATION

REPORT NUMBER

John H. Glenn Research Center at Lewis Field

E-16070

Cleveland, Ohio 44135-3191

\section{SPONSORING/MONITORING AGENCY NAME(S) AND ADDRESS(ES)}

National Aeronautics and Space Administration

Washington, DC 20546-0001

\begin{tabular}{|c|}
\hline $\begin{array}{l}\text { ACRONYM(S) } \\
\text { NASA; AIAA }\end{array}$ \\
\hline $\begin{array}{l}\text { 11. SPONSORING/MONITORING } \\
\text { REPORT NUMBER } \\
\text { NASA/TM-2007-214908; AIAA-2006 } \\
\end{array}$ \\
\hline
\end{tabular}

\section{DISTRIBUTIONIAVAILABILITY STATEMENT}

Unclassified-Unlimited

Subject Categories: 07, 02, and 12

Available electronically at http://gltrs.grc.nasa.gov

This publication is available from the NASA Center for AeroSpace Information, 301-621-0390

\section{SUPPLEMENTARY NOTES}

\section{ABSTRACT}

In a gas turbine engine, the turbine rotor blades are buffeted by the wakes of the vanes located upstream. There is a transient effect from the passing of wakes on the blade heat transfer. This transient effect has been computed for a representative rotor by introducing a wake upstream via an unsteady inlet flow boundary condition, or "gust" condition. Two cases of turbulent flow and laminar flow with Reynolds numbers of 385,000 and 385 respectively were considered. For the turbulent flow case a quasi-steady calculation was also performed. The variation in the unsteady heat transfer coefficient was found to be as high as 120 percent of the mean. For the turbulent flow case a quasisteady calculation was also performed. The time mean of the unsteady heat transfer, the mean of the quasi-steady variations and the steady results agree reasonably well on all blade locations except for the turbulent results which differ near the leading edge. The quasi-steady heat transfer results do not agree with the instantaneous unsteady results, although the time-mean values are similar.

\section{SUBJECT TERMS}

Unsteady heat transfer; Rotor blades; Quasi steady

\section{SECURITY CLASSIFICATION OF:}

a. REPORT

$\mathrm{U}$

b. ABSTRACT

$\mathrm{U}$

\section{LIMITATION OF} ABSTRACT

18. NUMBER
OF
PAGES
15

19a. NAME OF RESPONSIBLE PERSON
Ali A. Ameri
19b. TELEPHONE NUMBER (include area code)
216-433-8346

Standard Form 298 (Rev. 8-98) Prescribed by ANSI Std. Z39-18 

